nhóm 1 cao hơn đáng kể so với nhóm 2 tại các thời điểm 8 giờ, 12 giờ, 16 giờ và 24 giờ sau phẫu thuật.

Nhóm 2 có tỉ lê rất hài lòng và hài lòng lần lượt là $90 \%$ và $10 \%$, nhóm 1 lần lượt tương ứng là $80 \%$ và $20 \%, \mathrm{p}<0,05$.

Tỷ lệ nôn ở nhóm 1 chiếm $20 \%$ cao hơn nhiều so với nhóm 2 chỉ chiếm $4 \%, p<0,05$.

Các chỉ số lâm sàng liên quan đến tuần hoàn trong giới hạn bình thường và tương đương nhau giữa hai nhóm ở các thời điểm 1 giờ, 2 giờ , 4 giờ nghiên cứu.

Nhịp tim, HA trung bình lúc 8 giờ, 12 giờ, 16 giờ và 24 giờ sau phẩu thuật ở nhóm 1 cao hơn đáng kể so với bệnh nhân nhóm $2(p<0,05)$.

Các chỉ số lâm sàng liên quan đến hô hấp trong giới hạn bình thường và tương đương nhau giữa hai nhóm ở tất cả các thời điểm nghiên cứu.

Trong nghiên cứu của chúng tôi không gặp bất kỳ tai biến nào liên quan đến gây tê TAP block.

\section{TÀl LIỆ THAM KHẢO}

1. B. Richez, L. Ouchchane, A. Guttmann và các cộng sự. (2015), "The Role of Psychological Factors in Persistent Pain After Cesarean Delivery", J Pain, 16(11), tr. 1136-46.
2. Uma Hariharan và Vinoth Natarajan (2017), "Rectus Sheath Block and Transversus Abdominis Plane Block for Pain Relief after Cesarean Section".

3. Zhirajr Mokini Poturljan (2011), Ultrasound Blocks for the Anterior Abdominal Wall Principles and Implementation for Adult and Pediatric Surgery. 2011 Edition.

4. P. Hebbard (2015), "TAP block nomenclature", Anaesthesia, 70(1), tr. 112-3.

5. C. Pehora, A. M. Pearson, A. Kaushal và các cộng sự. (2017), "Dexamethasone as an adjuvant to peripheral nerve block", Cochrane Database Syst Rev, 11(11), tr. Cd011770.

6. A. Zorrilla-Vaca và J. Li (2018), "Dexamethasone Injected Perineurally is More Effective than Administered Intravenously for Peripheral Nerve Blocks: A Meta-Analysis of Randomized Controlled Trials", Clin J Pain, 34(3), tr. 276-284.

7. A. Gupta, A. Gupta và N. Yadav (2019), "Effect of dexamethasone as an adjuvant to ropivacaine on duration and quality of analgesia in ultrasound-guided transversus abdominis plane block in patients undergoing lower segment cesarean section - A prospective, randomised, single-blinded study", Indian J Anaesth, 63(6), tr. 469-474.

8. P. L. Petersen, O. Mathiesen, P. Stjernholm và các cộng sự. (2013), "The effect of transversus abdominis plane block or local anaesthetic infiltration in inguinal hernia repair: a randomised clinical trial", Eur J Anaesthesiol, 30(7), tr. 415-21.

\title{
ĐĂC ĐIỂM LÂM SÀNG CỦA THAI PHỤ SẨY THAI LIÊN TIẾP KHÔNG Rõ NGUYÊN NHÂN MANG GEN METHYLENETETRAHYDROFOLATE REDUCTASE BỆNH LÝ
}

\section{TÓM TẮT}

Nguyên nhân sẩy thai liên tiếp rất phức tạp và khó xác định, trong đó đa hình đơn gen MTHFR bệnh lý (C677T, A1298C) là một nguyên nhân mới cần tìm hiểu. Nghiên cứu nhằm: Xác định mối liên quan giữa MTHFR và bệnh lý sảy thai liên tiếp; Mô tả đặc điểm lâm sàng của những thai phụ có tiên sử sảy thai liên tiếp mang gen MTHFR (C677T và A1298C) bệnh lý. Đây là 1 nghiên cứu bệnh- chứng, 2 nhóm đều được xác định kiểu gen của gen MTHFR C677T/A1298C bằng phương pháp PCR. Nghiên cứu thu được 43 thai phụ thuộc nhóm bệnh và 30 thai phụ thuộc nhóm chứng. Thời điểm thai sẩy trung bình trong tiền sử của nhóm mang kiểu gen bệnh lý là 8,47 tuân. MTHFR

\footnotetext{
${ }^{1}$ Trường Đại học Y Hà Nội

${ }^{2}$ Bệnh viện Đa khoa Quốc Tế Vinmec Times City

Chịu trách nhiệm chính: Lê Thị Anh Đào

Email: leanhdao1610@gmail.com

Ngày nhận bài: 10.8.2021

Ngày phản biên khoa họ: 11.10.2021

Ngày duyệt bài: 20.10.2021
}

\section{Lê Thị Anh Đào', Nguyễn Thị Hằng ${ }^{2}$}

C677T làm tăng nguy cơ xuất hiện triệu chứng doa sẩy thai trong 3 tháng đâu $(p=0,043)$. Kết luận: Đà hình đơn gen MTHFR C677T tăng xuất hiện triệu chứng doa sẩy thai trong 3 tháng đâu.

Tư khoá: MTHFR C677T, MTHFR A1298C, sẩy thai liên tiếp không rõ nguyên nhân

\section{SUMMARY \\ CLINICAL FEATURES OF UNEXPLAINED RECURRENT PREGNANCY LOSS WOMEN CARRYING ABNORMAL MTHFR POLYMORPHISM GENE}

Unexplained RPL has been a challenging issue in diagnosis. Methylenetetrahydrofolate reductase (MTHFR) gene polymorphisms (C677T, A1298C) are believed to be risk of unexplained recurrent pregnancy loss. This study aims to describe the clinical signs of women with recurrent pregnancy loss and MTHFR polymorphism gene. This is a case-control study was performed on 2 groups. Both two groups were evaluated for the presence of MTHFR gene polymorphisms by PCR technique. Result: A total of 43 cases and 30 controls were identified. The gene 
carrying group had earlier miscarriage time in the history 8.47 weeks. MTHFR C677T polymorphism gene was increased the risk of miscarriage symptoms in the first trimester (abdominal pain: $\mathrm{OR}=5.6,95 \% \mathrm{CI}$ : 1.1 28.6, $p=0.038$, vaginal bleeding: $\mathrm{OR}=3.6,95 \% \mathrm{CI}$ : 1.0-12.5, $p=0.043)$. Conclusion: MTHFR C677T gene polymorphism is associated with increased risk of URPL in Vietnamese women and miscarriage symptoms in the first trimester.

Key words: MTHFR C677T, MTHFR A1298C, polymorphism, Unexplained recurrent pregnancy loss

\section{I. ĐĂT VẤN ĐỀ}

Sẩy thai liên tiếp (STLT) là tình trạng sẩy thai tự nhiên từ 2 lần liên tiếp trở lên, gặp ở quần thể thai nghén với tỷ lệ 1-5\% ${ }^{1}$. Cơ chế bệnh sinh của bệnh vẫn chưa được biết rõ, nhiều nguyên nhân với sự tham gia của các yếu tố di truyền, miễn dịch, môi trường, nội tiết ${ }^{2}$. Có khoảng hơn $50 \%$ các trường hợp không tìm thấy nguyên nhân bằng các xét nghiệm hiện có ${ }^{1}$.

Một trong những nguyên nhân gây sẩy thai và STLT là rối loạn đông máu, thực chất là tình trạng tăng đông quá mức. Khi mang thai, cơ thể người phụ nữ ở trong trạng thái tăng đông nhẹ do việc tăng hoạt động của các yếu tố đông máu và sự ức chễ hoạt động của các yễu tố chống đông máu, đây được coi là quá trình tăng đông sinh lý và sẽ giúp ích trong việc làm tổ và phát triển của thai nhi. Tuy nhiên, khi quá trình tăng đông máu diễn ra quá mạnh mẽ, hay gặp trong các trường hợp rối loan đồng máu liên quan đến các gen đông máu, dẩn tới việc hình thành huyết khối trong lòng mạch. Vị trí thường gặp huyết khối chính là các động/tĩnh mạch của bánh rau, dẫn tới hạn chế lượng máu và chất dinh dưỡng đến cung cấp cho thai, điều này sẽ dẫn đến các biên chứng thai kỳ như sẩy thai, thai lưu, thai chậm phát triển trong tử cung, đẻ non ${ }^{3}$.

Các bệnh lý rối loạn đông máu thường gặp nhất là đột biến gen trội yếu tố $V$ Leiden, yếu tố V R2, đột biến gen prothrombin F II G20210A và đa hình đơn gen methylenetetra hydrofolateredutase C677T (MTHFR), đa hình đơn gen MTHFR A1298C, đa hình đơn gen Plasminogen activator inhibitor-1 (PAI-1). Đa số các rối loạn này thường gặp hợn ở người da trắng. Ngược lại với người châu Á, đa hình đơn gen MTHFR là thường gặp hơn cả ${ }^{4}$. Các đa hình đơn gen MTHFR C677T và $A 1298 C$ khi xuất hiện làm cho hoạt động của enzyme MTHFR giảm đi. Dạng đồng hợp tử MTHFR 677TT và 1298CC được chứng minh là nguyên nhân gây tăng homocysteine trong máu, làm tăng nguy cơ hình thành huyết khối trong lòng mạch lên 3 lần ${ }^{5}$. Đa hình đơn gen MTHFR C677T và A1298C được cho là nguy cơ gây STLT, đặc biệt là các trường hợp STLT không rõ nguyên nhân 6 .

Tại Việt Nam, trong thời gian gần đây, nhiều bệnh viện và các trung tâm xét nghiệm đã bắt đẩu triển khai việc xét nghiệm một vài gen gây rối loạn đông máu ở những bệnh nhân STLT. Nghiên cứu của chúng tôi nhằm 2 mục tiêu: (1) Xác định tỷ lê mang đa hình đơn gen MTHFR trong quần thể thai phụ nữ có tiền sử STLT tai bệnh viện Phụ Sản Hà Nội và (2) Mô tả đặc điểm lầm sàng của những trường hợp STLT có liên quan đến gen MTHFR

\section{II. ĐỐI TƯỢNG VÀ PHƯƠNG PHÁP NGHIÊN CỨU \\ 1. Đối tượng nghiên cứu}

Tiêu chuẩn lựa chọn nhóm bệnh: lựa chọn những thai phụ mới có thai từ 5 tuần trở lên thoả mãn các tiểu chuẩn: (1) có tiền sử sẩy thai từ 2 lần liên tiếp trở lên, (2) không tìm thấy nguyên nhân gây STLT bằng các xét nghiệm hiện có, (3) đồng ý tham gia nghiên cứu. (Các xét nghiêm sàng lọc nguyên nhân sảy thai gồm có: 3 kháng thể kháng phospholipid; xét nghiệm T3, T4, TSH và nhiễm sắc đồ 2 vợ chồng, siêu âm đầu dò âm đạo hoặc kết quả chụp buồng tử cung soi buồng tử cung trước đó nếu có đều được chấp nhận).

Tiêu chuẩn lựa chọn nhóm chứng: lựa chọn các thai phụ thoả mãn các tiêu chuẩn: (1) khồng có tiền sử STLT, (2) đã có ít nhất 01 lần sinh con sống, (3) đồng ý tham gia nghiên cứu.

Tiêu chuân loaí trứ: loại trừ một trong các trường hợp sau: (1) thai phụ mắc các bệnh lý mạn tính nă̆ng, (2) các trường hợp STLT đã tìm thấy nguyên nhân khác, (3) không đủ dữ liệu nghiên cứu.

\section{Phương pháp nghiên cứu}

Thiết kế nghiên cứu: nghiên cứu bệnh chứng (case - control study).

Cách tiến hành nghiên cứu:

- Bước 1: Lựa chọn nhóm nghiên cứu: Những thai phụ có tiền sử STLT được làm các xét nghiệm chẩn đoán nguyên nhân gây sẩy thai. Những trường hợp tìm thây nguyên nhân (bất thường nhiễm sắc thể, bất thường tử cung, hội chứng Antiphospholipid, lupus, các rối loạn miến dịch khác, rối loạn nội tiết, rối loạn đông máu đã được chẩn đoán) được loại khỏi nghiên cứu. Những thai phụ STLT không tìm thấy nguyên nhân bằng các xét nghiệm đã nêu được lấy vào nhóm bệnh. Những thai phụ không có tiền sử STLT thoả mãn tiêu chuẩn lựa chọn nhóm chứng được lấy vào nhóm chứng.

- Bước 2: Các thai phụ thuộc cả 2 nhóm 
nghiên cứu được hỏi tiền sử, khám, siêu âm, làm xét nghiệm xác định kiểu gen của MTHFR 677, MTHFR 1298. Kiểu gen MTHFR 677 và MTHFR 1298 được xác định bằng phương pháp ARMSPCR tại Trung tâm Chẩn đoán trước sinh, Bệnh viện Phụ Sản Hà Nội.

- Bước 3: Làm sạch số liệu, phân tích và đưa ra kết quả nghiên cứu dựa trên những thông tin thu được.

- Xï lý số Iiệu: số liệu được quản lý trên phân mềm SPSS 20.0. Sử dụng các phương pháp thống kê trong y học (t test, test Chi bình phương) để so sánh giữa các trung bình, tỷ lệ. Tính toán tỷ số OR và khoảng tin cậy 95\%CI của gen MTHFR C677T, MTHFR A1298C với tình trạng STLT KRNN.

- Thời gian và địa điểm nghiên cứu: Nghiên cứu được thực hiện tại Bệnh viện Phụ Sản Hà
Nội, bắt đâu từ tháng $1 / 2019$ đến hết tháng 8/2019.

3. Đạo đức nghiên cứu. Đề tài được hội đồng khoa học bệnh viện Phụ Sản Hà Nội thông qua quyết định số 880QĐ/PS- TTDT CDT 25/6/2018. Các thông tin của bệnh nhân được giữ kín và chỉ phục vụ cho mục đích nghiên cứu.

\section{KẾT QUẢ NGHIÊN CỨU}

Từ tháng $1 / 2019$ đến tháng 8/2019, nghiên cứu thu nhận được tổng số 103 thai phụ (73 thai phụ có tiền sử sẩy thai liên tiếp (bao gồm 43 thai phụ STLT không rõ nguyên nhân (STLTKRNN) thuộc nhóm bệnh và 30 thai phụ STLT đã tìm thâyy nguyên nhân), 30 thai phụ khoẻ mạnh thuộc nhóm chứng). Cả nhóm bệnh và nhóm chứng đều không có sự khác biệt về tuổi, chiều cao, cân nặng và chỉ số khối cơ thể (BMI).

Bảng 1: Tỷ lệ kiểu gen trong nghiên cứu

\begin{tabular}{|c|c|c|c|c|c|c|}
\hline & \multicolumn{3}{|c|}{ MTHFR C677T } & \multicolumn{3}{c|}{ MTHFR A1298C } \\
\cline { 2 - 7 } & TT & CT & CC & CC & CA & AA \\
\hline Nhóm bệnh & $14(32,6 \%)$ & $15(32,8 \%)$ & $14(32,6 \%)$ & $5(11,7 \%)$ & $17(39,5 \%)$ & $21(48,8 \%)$ \\
\hline Nhóm chứng & $3(10 \%)$ & $11(36,7 \%)$ & $16(53,3 \%)$ & $3(10 \%)$ & $11(36,7 \%)$ & $16(53,3 \%)$ \\
\hline p & \multicolumn{3}{|c|}{$\mathbf{0 , 0 4 9}$} \\
\hline
\end{tabular}

Kết quả nghiên cứu cho thấy MTHFR C677T có liên quan đến bệnh lý STLT không rõ nguyên nhân, còn MTHFR A1298C thì không có mối liên quan.

Bảng 2. Liên quan giữa các đa hình đớn gen và STLT KRNN

\begin{tabular}{|c|c|c|c|c|}
\hline \multicolumn{2}{|c|}{ Kiểu gen } & OR & $\mathbf{9 5 \%} \mathbf{C I}$ & $\mathbf{p}$ \\
\hline \multirow{3}{*}{ MTHFR C677T } & TT với CT + CC & $\mathbf{3 , 2 5 6}$ & $\mathbf{1 , 0 2 4 - \mathbf { 1 0 } 3 5}$ & $\mathbf{0 , 0 2 8}$ \\
\cline { 2 - 5 } & TT + CT với CC & 2,367 & $0,907-6,182$ & 0,065 \\
\cline { 2 - 5 } & Alen T với alen C & $\mathbf{2 , 5 2 9}$ & $\mathbf{1 , 2 5 3 - \mathbf { 5 , 1 0 8 }}$ & $\mathbf{0 , 0 0 9}$ \\
\hline \multirow{2}{*}{ MTHFR } & CC với CA + AA & 1,184 & $0,261-5,382$ & 1 \\
\cline { 2 - 5 } A1298C & CC + CA với AA & 1,197 & $0,471-3,046$ & 0,813 \\
\cline { 2 - 5 } & Alen C với alen A & 1,158 & $0,562-2,385$ & 0,718 \\
\hline
\end{tabular}

Alen T và kiếu gen TT tại vị trí 677 trên gen MTHFR có liên quan đến sảy thai liên tiếp.

Bảng 3. Sốlân sây thai trung bình của nhóm bệnh

\begin{tabular}{|c|c|c|c|}
\hline & $\mathbf{n}$ & Trung bình (lîan) ( $X \pm$ SD) & $\mathbf{p}$ \\
\hline Cả nhóm bệnh & 43 & $2,91 \pm 1,2$ & \\
\hline Mang gen MTHFR bệnh lý & 39 & $2,97 \pm 1,22$ & \\
\hline Không mang gen MTHFR bệnh lý & 4 & $2,28 \pm 0,5$ & 0,05 \\
\hline
\end{tabular}

Nhóm STLT KRNN mang gen MTHFR xu hướng bệnh lý (677TT, 677CT, 1298CC, 1298CA) có số lân sẩy thai trung bình là 2,97 lần, cao hơn nhóm STLT KRNN không mang gen MTHFR 677 CC và 1298 AA (2,28 lần) với $p=0,05$.

Bảng 4. Thởi điểm thai sẩy trong tiền sử của nhóm bệnh

\begin{tabular}{|c|c|c|c|}
\hline & $\mathbf{n}$ & Trung bình (tuân) $(X \pm S D)$ & $\mathbf{p}$ \\
\hline Cả nhóm bệnh & 43 & $8,61 \pm 2,1$ & \\
\hline Mang gen MTHFR & 39 & $8,47 \pm 2,0$ & \\
\hline Không mang gen MTHFR & 4 & $9,95 \pm 3,2$ & 0,194 \\
\hline
\end{tabular}

Không có sự khác biệt về thời điếm thai sấy trong tiền sử giữa nhóm STLT KRNN mang gen MTHFR xu hướng bệnh lý với nhóm không mang gen.

Bảng 5. Liên quan của MTHFR và mốt số triệu chứng lâm sàng

\begin{tabular}{|c|c|c|c|c|}
\hline \multirow{2}{*}{ Đặc điểm } & \multicolumn{2}{|c|}{ MTHFR C677T } & \multicolumn{2}{c|}{ MTHFR A1298C } \\
\cline { 2 - 5 } & OR (95\%CI) & P & OR (95\%CI) & p \\
\hline Đau bụng & $\mathbf{5 , 6 ( 1 , 1 - 2 8 , 6 )}$ & $\mathbf{0 , 0 3 8}$ & $0,94(0,25-3,55)$ & 1 \\
\hline
\end{tabular}


VIETNAM MEDICAL JOURNAL N²0 - NOVEMBER - 2021

\begin{tabular}{|c|c|c|c|c|}
\hline Ra máu âm đạo & $\mathbf{3 , 6}(\mathbf{1 - 1 2} \mathbf{3})$ & $\mathbf{0 , 0 4 3}$ & $0,74(0,19-2,91)$ & 0,736 \\
\hline Sấy thai trước 8 tuần & $1,44(0,52-4)$ & 0,327 & $0,36(0,01-1,63)$ & 0,281 \\
\hline Sây thai sau 12 tuần & $0,81(0,25-2,6)$ & 0,772 & $0,94(0,25-3,55)$ & 1 \\
\hline $\begin{array}{c}\text { Đái tháo đường thai kỳ, } \\
\text { tiền sản giật }\end{array}$ & $1,83(0,16-21,1)$ & 0,543 & $0,95(0,17-5,31)$ & 1 \\
\hline
\end{tabular}

MTHFR C677T làm tăng nguy cơ xuất hiện triệu chứng: đau bụng, ra máu âm đạo lên 5,6 lần và 3,6 lân.

\section{BÀN LUẬN}

Chứng huyết khối di truyền đã được chứng minh có liên quan đến các biến chứng sản khoa khác nhau như: sẩy thai liên tiếp, thai chết lưu, thai chậm phát triển trong tử cung, sinh non, tiền sản giật, rau bong non. Khoảng 66\% số phụ nữ STLT được tìm thây có huyết khối kèm theo ${ }^{7}$. Enzyme MTHFR là một enzyme điều hoà chính trong chu trình chuyển hoá folate và homocysteine. Các đa hình đơn gen bệnh lý của gen MTHFR làm giảm hoạt tính của enzyme MTHFR. Kiểu gen đồng hợp tử MTHFR 677TT làm hoạt tính của enzyme MTHFR giảm xuống còn khoảng 30-40\% bình thường; với kiểu gen dị hợp tử 677CT và đồng hợp tử 1298CC, hoạt tính của enzyme còn $60-70 \%$ bình thường ${ }^{8,9}$. Khi hoat tính của MTHFR giảm này làm tăng nồng độ homocysteine trong máu, dẫn đến tăng nguy cơ hình thành các cục máu đông trong lòng mạch, làm gián đoạn tuần hoàn tại tử cung - rau, tăng nguy cơ sẩy thai. Quá trình này diển ra liên tục không ngừng nên hậu quả là dấn đến tình trạng STLT. Hoạt tính của enzyme MTHFR càng giảm thì nồng độ homocysteine trong máu càng cao, nguy cơ gầy ra bệnh lý càng tăng ${ }^{8}$. Nồng độ homocystein trong máu cao đã được chứng minh là nguy cơ gây ra nhiều bệnh lý khác như bệnh mạch vành, dị tật ống thần kinh ở trẻ, tiền sản giật, nhiều bệnh lý ung thư khác ${ }^{5}$ và làm tăng nguy cơ sẩy thai liên tiếp.

Trong nghiên cứu này, với 43 phụ nữ thuộc nhóm bệnh và 30 phụ nữ thuộc nhóm chứng không có sự khác biệt về tuổi, cân nặng, chiều cao và chỉ số khối cớ thể, chúng tôi nhận thấy kiểu gen đồng hợp tử MTHFR 677TT làm tăng nguy cơ STLT KRNN lên 3,256 lần (95\%CI: 1,02$10,35, p=0,028)$, alen $T$ của đa hình đơn gen MTHFR C677T làm tăng nguy cơ STLT KRNN lên 2,529 lần ( $95 \% \mathrm{CI}$ : 1,25-5,1, $\mathrm{p}=0,009)$. Chen (2016) cũng nhận thấy MTHFR 677TT làm tăng nguy cơ STLT ở phụ nữ Trung Quốc lên 2,36 lần. Nguy cơ này ở phụ nữ châu Á là 1,61 lần theo Rai ${ }^{6}$. Vai trò của đa hình đơn gen MTHFR A1298C với bệnh lý STLT còn nhiều tranh cãi. Có nhiều nghiên cứu ủng hộ quan điểm MTHFR A1298C liên quan đến bệnh lý STLT mặc dù mức độ liên quan không chặt chẽ bằng MTHFR C677T. Nhưng đồng thời cũng có nhiều nghiên cứu cho rằng MTHFR $A 1298 C$ không liên quan đến tình trạng STLT. Nghiên cứu của chúng tôi cũng có đồng quan điểm với một số tác giả khác khi chỉ ra rằng MTHFR A1298C không liên quan đến tình trạng STLT. Một nghiên cứu khác chỉ ra rằng những phụ nữ mang cả 2 đa hình đơn gen này làm tăng nguy cơ sẩy thai lên 4,996 lần (95\%CI: 1,65-12,129). Như vậy, bước đầu có thể nhận định rằng: đa hình đơn gen MTHFR C677T có liên quan đến tình trạng STLT KRNN trong nghiên cứu này.

Các nghiên cứu về STLT và đa hình đơn gen MTHFR trước đây đều chưa đề cập đến các đặc điểm lâm sàng của những bệnh nhân STLT mang gen MTHFR xu hướng bệnh lý. Nghiên cứu của chúng tôi nhận thấy nhóm STLT mang gen MTHFR xu hướng bệnh lý và nhóm không mang gen không có sự khác biệt về thời điểm thai sấy trong tiên sử nhưng nhóm mang gen có số lần sẩy thai trong tiền sử là 2,97 lần nhiều hơn so với nhóm không mang gen là 2,28 lần $(p=0,05)$. Nhóm STLT mang gen có thời điểm thai sây trong tiền sử trung bình là 8,47 tuần, không khác biệt so với STLT không mang gen bệnh lý.

Đa hình đơn gen MTHFR C677T làm tăng nguy cơ xuất hiện các triệu chứng của doạ sẩy thai trong 3 tháng đầu (tẳng nguy cơ xuất hiện triệu chứng đau bụng lên 5,6 lần, $p=0,038$, tăng nguy cơ xuất hiện triệu chứng ra máu âm đạo lên 3,6 lần, $p=0,043)$, điều này có thể do việc gia tăng sự hình thành các cục máu đông trong lòng mạch, dẫn tới thiếu máu bánh rau, từ đó làm sản sinh các chất như bradylkinine, prostaglandin vào máu, dẫn tới triệu chứng lâm sàng đau bụng và ra máu. Khi đánh giá mối liên quan với các yếu tố khác, chúng tôi nhận thấy đa hình đơn gen MTHFR C677T/A1298C không làm gia tăng tình trạng sẩy thai trước 8 tuần, tình trạng sẩy thai sau 12 tuân, và không làm tăng tỷ lệ xuất hiện đái tháo đường, tiền sản giật sớm trong thai kỳ (dưaa trên những thai kỳ trước đó). Trong khi đó, các tác giả khác lại cho rằng đa hình đớn gen MTHFR C677T làm tăng nguy cơ xuất hiên tiền sản giật trong thai kỳ lên 2,2 lần. Có thể do cỡ mẫu nghiên cứu của chúng tồi chưa đủ lớn, nên kết quả nghiên cứu có thể còn chưa thật sự chính xác. Để đảm bảo kết quả tin cậy, khoa học hơn cần có một nghiên cứu tiếp 
tục với cõ mẫu lớn hơn nữa.

\section{KẾT LUẬN}

Đa hình đơn gen MTHFR C677T làm tăng nguy cơ STLT KRNN. Nhóm STLT KRNN mang gen MTHFR có xu hướng bệnh lý có số lần sấy thai trong tiền sử trung bình là 2,97 lần, cao hơn nhóm không mang gen 2,28 lần $(p=0,05)$, thời điểm thai sẩy trung bình trong tiền sử của nhóm mang gen là 8,47 tuần.

MTHFR C677T làm tăng nguy cơ xuất hiện triệu chứng doạ sẩy thai trong 3 tháng đâuu (tăng nguy cơ đau bụng 5,6 lần $(p=0,038)$, tăng nguy cơ ra máu âm đạo 3,6 lần $(p=0,043))$.

\section{TÀI LIỆU THAM KHẢO}

1. Practice Committee of the American Society for Reproductive Medicine. Evaluation and treatment of recurrent pregnancy loss: a committee opinion. Fertility and Sterility. 2012; vol. 98, (5), pp. 1103-1111.

\section{Balasubramaniam,}

Amarasekara.

Analysis

Kotalawala,

Methylenetetrahydrofolate Reductase (MTHFR) Polymorphisms (C677t \& A1298c) in Recurrent Pregnancy Loss (RPL). Nessa Journal of Gynecology.2017; vol. 1, no. 4, pp. 1-26, 2017.
3. Đỗ Tiến Dũng. Huyết khối và sảy thai liên tiếp. Tạp chí Y học lâmm sàng Bệnh viện Bạch Mai. 2010; vol. 50, pp. 12-16.

4. Barut MU, Bozkurt M, Kahraman M. Thrombophilia and Recurrent Pregnancy Loss: The Enigma Continues. Medical Science Monitor 2018; vol. 24, pp. 4288-4294.

5. SC Liew; ED Gupta, "Methylenetetrahydrofolate reductase (MTHFR) C677T polymorphism: Epidemiology, metabolism and the associated diseases," European Journal of Medical Genetics. 2015; vol. 58, pp. 1-10.

6. Vandana Rai. Methylenetetrahydrofolate Reductase C677T Polymorphism and Recurrent Pregnancy Loss Risk in Asian Population: A Metaanalysis. Indian Journal of Clinical Biochemistry. 2016; vol. 31, no. 4, pp. 402-413.

7. Tranquilli AL, Saccucci F, Giannubilo SR. Unexplained fetal loss: the fetal side of thrombophilia. Fertility and Sterility 2010; vol. 94, no. 378-380.

8. Liew S, Gupta E. Methylenetetrahydrofolate reductase (MTHFR) C677T polymorphism: Epidemiology, metabolism and the associated diseases. European Journal of Medical Genetics. 2015; vol. 58, pp. 1-10, 2015.

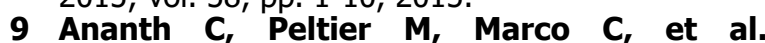
Associations between 2 polymorphisms in the methylenetetrahydrofolate reductase gene and placental abruption. American Journal of Obstetrics and Gynecology. 2007; vol. 197, no. 4, p. 385.

\title{
ĐA HÌNH ĐƠ'N NUCLEOTIDE RS2856718 CỦA GEN HLA-DQ TRÊN BỆNH NHÂN UNG THƯ BIỂU MÔ TẾ BÀO GAN
}

\author{
Mạc Thị Tịnh ${ }^{1,2}$, Nguyễn Trọng Tuệ ${ }^{1}, H_{\hat{̀}} C^{2}$ ẩm Tú ${ }^{1}$,
} Nguyễn Hoàng Việt ${ }^{1}$, Nguyễn Thu Thúy $^{1}$

\section{TÓM TẮT}

Ung thư gan nguyên phát là bệnh ung thư phổ biến và có tỉ lệ tử vong cao. Gen HLA-DQ mã hóa các chuối polypeptid của phân tử MHC Iớp II tham gia hoạt hóa tế bào trình diện kháng nguyên trong đáp ứng miễn dịch. Đa hình đơn nucleotide (SNP) rs2856718 của gen HLA-DQ có thể liên quan tới nhiễm virus viêm gan $B$ mãn tính và nguy cơ ung thư biểu mô tế bào gan. Nghiên cứu này được thực hiện nhằm mục tiêu xác định sự phân bố của SNP rs2856718, đồng thời đánh giá mối liên quan giữa SNP này với nguy cơ mắc ung thư biểu mô tế bào gan. Kỹ thuật RT-PCR được sứ dụng để xác định kiểu gen SNP rs2856718 trên 93 bệnh nhân ung thư biểu mô tế bào

${ }^{1}$ Trung tâm Nghiên cứu Gene - Protein, Trường Đại học Y Hà Nội

2̇rường Đại họ Y Hải Phòng

Chịu trách nhiệm chính: Nguyễn Thu Thúy

Email: nguyenthuthuy@hmu.edu.vn

Ngày nhận bài: 9.8.2021

Ngày phản biên khoa học: 8.10 .2021

Ngày duyệt bài: 15.10 .2021 gan và 93 người khỏe mạnh. Kết quả đã xác định được tỷ lệ kiểu gen $G G, A G, A A$ ở nhóm bệnh là $39,8 \%, 46,2 \%, 14 \%$ và nhóm chứng là $30,1 \%$, $53,8 \%, 16,1 \%$. Chưa tìm thấy mối liên quan giữa SNP rs2856718 với nguy cơ ung thư biểu mô tế bào gan cũng như với một số yếu tố nguy cơ khác.

Tư khóa: SNP, rs2856718, HLA-DQ, ung thư biểu mô tế bào gan.

\section{SUMMARY \\ SINGLE NUCLEOTIDE POLYMORPHISM RS2856718 IN HLA-DQ GENE ON HEPATOCELLULAR CARCINOMA PATIENTS}

Primary liver cancer is a common cancer with a high mortality rate. The HLA-DQ gene encodes polypeptide chains of MHC class II molecules involved in the activation of antigen-presenting cells in the immune response. The single nucleotide polymorphism (SNP) rs2856718 of HLA-DQ gene may be associated with chronic hepatitis $B$ virus infection and hepatocellular carcinoma (HCC). This study was aimed to determine the distribution of SNP rs2856718, and to evaluate the association between this SNP and the risk of HCC. RT-PCR technique was used to 